\title{
Ecologia Evolutiva e Conservação: uma Parceria Necessária
}

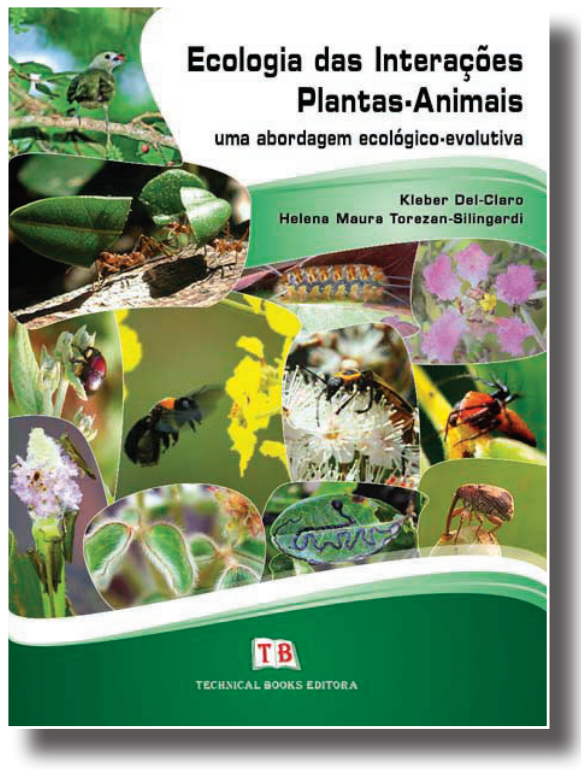

Os organizadores foram muito bem sucedidos em sua iniciativa. Trata-se de uma coletânea de capítulos escritos por pesquisadores brasileiros e estrangeiros. Cada um dos capítulos traz informações sobre a ecologia das interações entre plantas e animais em regiões tropicais. O livro preenche uma lacuna à espera, há cerca de 40 anos, por estudantes e professores brasileiros que se interessam pela abordagem. Durante boa parte desse intervalo de tempo, ecólogos brasileiros estudaram e ensinaram exemplos de interações plantas-animais publicados em revistas e livros escritos por pesquisadores norte-americanos (e.g. Daniel Janzen) que trabalharam especialmente em Costa Rica e Barro Colorado, Panamá. Todavia, os alunos da geração atual, além de dispor daqueles exemplos, dispõem da oportunidade de conhecer exemplos publicados por pesquisadores brasileiros e reunidos nesse livro. Ao mesmo tempo em que cumpre o papel de livro-texto, o volume testemunha parte da história da evolução da ecologia no Brasil. A maior parte das ilustrações, algumas com muita beleza, cumpre o seu papel de chamar a atenção do leitor, sobre vários aspectos considerados no volume. Contudo, em uma época na qual se dispõe de recursos editoriais sofisticados, algumas imagens poderiam ter sua qualidade aperfeiçoada. Finalmente, muitos dos capítulos que compõem o livro evidenciam a importância de estudos sobre a ecologia de interações ecológicas para subsidiar a conservação in situ e de paisagens degradadas por meio de atividades humanas.

A estrutura do livro traz um curto prefácio de Robert Ricklefs e abrange cinco partes: Introdução; Aspectos
Kleber Del-Claro \& Helena Maura TorezanSilingardi (orgs). Ecologia das Interações Plantas-Animais - uma abordagem evolutiva. Technical Books Editora, Rio de Janeiro, 2012, 333 p. ISBN: 9788561368227.

gerais e introdutórios às relações plantas-animaisquando predominam os antagonismos; Aspectos gerais e introdutórios às relações plantas-animais-quando predomina a cooperação; Exemplos especiais em interações plantasanimais e Sínteses e perspectivas futuras no estudo de interações plantas-animais.

Na introdução, Kleber Del-Claro discorre de forma sucinta sobre as origens e a importância das interações plantasanimais para a ecologia e conservação. Ressalta que a história evolutiva da biodiversidade é essencialmente a história da evolução das interações entre espécies. O autor apresenta questões amplas e complexas que exigem estudos abrangentes e esforços cooperativos para que possam ser satisfatoriamente respondidas e úteis a propósitos conservacionistas. No entanto, a caracterização da complexidade das interconexões entre sistemas de interação e a abordagem teórica parece-me insuficente. Nota-se o empenho do mesmo em tentar estabelecer os vínculos teóricos entre os capítulos, apesar de tais vínculos não serem suficientemente explícitos para que os alunos-leitores concebam o desenho do eixo teórico que conduz e manteria a unidade da abordagem. Independentemente dessa dificuldade, no entanto, a linguagem acessível, os exemplos e as menções que Del-Claro faz sobre os capítulos servem como um bom roteiro para a leitura dos capítulos individuais e podem, pelos menos, servir como gatilhos para "insights" sobre a percepção da importância dessas questões teóricas.

A parte II inclui três capítulos dedicados a ilustrar as interações antagônicas entre plantas e animais. Robert J. 
Marquis (capítulo 2) apresenta um panorama abrangente sobre o universo de defesas que plantas apresentam contra a ação de herbívoros. Seu capítulo se estrutura na classificação proposta por Boege \& Marquis (2005) de características que influenciam os níveis de vulnerabilidade de plantas à ação dos herbívoros: escape, defesa e tolerância. Creio que o capítulo 6 (O movimento dos animais frugívoros e das sementes em paisagens fragmentadas) estaria melhor localizado caso viesse imediatamente após este capítulo. De qualquer forma, embora o capítulo 2 seja uma boa introdução sobre o tema e o autor mencione que muitas das idéias que apresentou foram baseadas na formulação original das teorias a respeito, seria útil que apresentasse quais foram as teorias mais influentes que estimularam a expansão desses estudos.

A este, dois capítulos mais específicos se seguem. José Roberto Trigo, Martin Pareja \& Kamila Ferreira Massuda (capítulo 3) também partem da classificação, categorizando substâncias químicas produzidas pelo metabolismo secundário em plantas. Apesar de iniciar o capítulo enfatizando as estruturas químicas dos principais compostos, em vez da teoria, os autores exploram em maiores detalhes aspectos das interações diretas entre herbívoros e plantas, mas também o papel das substâncias químicas nas interações que envolvem a ação de parasitos e predadores. Os autores ressaltam que estudos desenhados para identificar as pressões seletivas responsáveis pela evolução do metabolismo secundário são primordiais em uma abordagem ecológico-evolutiva sobre interações ecológicas. Trata-se de um bom capítulo para estimular o interesse em ecologia química das interações entre plantas, herbívoros e seus parasitos e predadores.

O capítulo conclusivo da parte II (capítulo 4), assinado por Maria Alice S. Alves, Maurício B. Vecchi, Vanessa C. Tomaz \& Augusto João Piratelli, discute o impacto de vertebrados terrestres sobre a comunidade vegetal, tomando aves como exemplo. O capítulo é bem documentado com exemplos bem ilustrativos. Do ponto de vista do manejo e conservação, os autores discutem a influência positiva de vertebrados na manutenção da produtividade em áreas agrícolas.

Helena Maura Torezan-Silingardi (capítulo 5) aborda a história natural da polinização. Embora o capítulo contenha numerosas informações de qualidade, Torezan-Silingardi preocupou-se excessivamente em descrições e definições, como por exemplo, características morfológicas gerais de flores. Além disso, a tabela que descreve síndromes de polinização traz um excesso de informações que poderia ser resumido sem comprometer a qualidade do capítulo. O seu esforço em apresentar um panorama abrangente das interações plantas-polinizadores certamente contribuirá para estimular alunos a se interessarem por este tema. Porém, esse estímulo poderia ser amplificado por meio de um texto que expressasse dinamicamente como o estudo sobre a história natural das interações polinizadores-plantas é importante para entender a evolução de coadaptações.
Marco Aurélio Pizo (capítulo 6) aborda o movimento de animais frugívoros e sementes em paisagens fragmentadas. Pizo seleciona três hipóteses para entender como os benefícios podem superar os custos da produção de frutos atrativos aos animais dispersores e se estabelecer como adaptações. Embora tais hipóteses sejam pontos de partida adequados para se abordar o tema, uma discussão mais detalhada sobre a plausibilidade de cada uma dessas para explicar o fenômeno seria bem-vinda. Pizo chama ainda atenção que o conhecimento sobre a movimentação de plantas e animais, em paisagens fragmentadas por influência de atividades humanas, é limitado e, por isso precisa ser mais estudada.

Paulo S. Oliveira, Sebastian F. Sendoya \& Kleber Del-Claro assinam o capítulo 7. É um capítulo exemplar sobre o papel desempenhado pelos estudos experimentais, em condições naturais, para a compreensão sobre interações entre plantas-animais: neste caso interações entre formigas, homópteros e plantas. Porém, tal qual fez Pizo, estes autores economizaram espaço e um maior detalhamento, talvez incluindo uma breve história da evolução da hipótese do mutualismo, poderia tornar ainda mais atrativo o capítulo.

Karina Lucas Silva-Brandão \& André Victor Lucci Freitas discorreram sobre interações entre borboletas e plantas (capítulo 8). Ao invés de explorar as discussões sobre as condições seletivas que poderiam influenciar na evolução de tais adaptações, os autores optaram por uma discussão mais geral sobre sistemática filogenética da interação entre borboletas e plantas, o que sem dúvida tem contribuído para entender a coevolução das interações. O capítulo é bem didático e ilustrativo e contribui para aumentar as possibilidades de que os leitores ampliem seu conhecimento sobre diferentes modos de se explorar, cientificamente, uma interação ecológica tão freqüente e importante na estruturação e funcionamento de ecossistemas vegetais terrestres.

Talvez a interação mais íntima entre animais e plantas seja a que ocorre entre plantas e insetos galhadores. Esse é o tema abordado por Jean Carlos Santos, Marco Antônio A. Carneiro \& Geraldo Wilson Fernandes (capítulo 9). Ao invés de adotarem uma abordagem experimental, tal a qual a descrita no capítulo 7, optaram pela exposição de seus próprios estudos sobre as variações ambientais em riqueza de espécies de galhadores que vivem em plantas de ambientes sob forte restrições ambientais (e.g. estresse higrotérmico).O capítulo traz ainda discussões importantes resultantes de testes de hipóteses sobre padrões de distribuição geográfica global de galhadores, o que proporcionará ao leitor uma oportunidade comparativa abrangente sobre os contrastes geográficos da diversidade em espécies destes organismos. Esse capítulo é um exemplo do desenvolvimento da abordagem ecológico-evolutiva no Brasil tendo como modelo de estudo um sistema peculiar de interação entre plantas-animais. 
Os insetos eussociais, formigas, abelhas, vespas e cupins são expressivos em riqueza em espécies e biomassa em ecossistemas terrestres. Seria uma excelente oportunidade para que os alunos pudessem ler sobre a ecologia evolutiva de cupins. No entanto, Og De Souza, Paulo Felippe Cristaldo, Cassiano Sousa Rosa, Daniela Faria Florêncio \& Alessandra Marins (capítulo 10), já na introdução, deixam explícita a opção de desenvolver um capítulo apenas descritivo sobre aspectos básicos da biologia do grupo. Por este motivo, sobre o ponto de vista ecológico-evolutivo, esse capítulo é um dos mais desbalanceados do conjunto. Recomenda-se que em uma possível edição vindoura, aspectos da ecologiaevolutiva de insetos com organização social tão peculiar sejam abordados.

Interações de formigas-cortadeiras e plantas são abordadas por Inara R. Leal, Rainer Wirth \& Marcelo Tabarelli (capítulo 11). Os autores comentam a ambiguidade que espécies desse grupo apresentam com relações às plantas com as quais interage: a depender do contexto ecológico estes podem ser negativos ou positivos para as plantas. Embora não haja informações detalhadas sobre as possíveis ações seletivas, que espécies do grupo exerçam sobre espécies de plantas com as quais interagem, os autores enfatizam seu papel como espécies engenheiras que modificam o habitat criando nichos disponíveis a outras espécies. O capítulo é de boa qualidade, não apenas pela diversidade de informações relevantes, mas pelo modo coerente e dinâmico pelo qual tais informações foram tratadas.

O que Gustavo Quevedo Romero \& João Vasconcelos Neto evidenciam no capítulo 12 é que interações entre aranhas e plantas podem ser bastante relevantes sob vários aspectos ecológicos-evolutivos. Nesse aspecto, os autores descrevem seus estudos pioneiros sobre o mutualismo digestivo que certas espécies de aranhas mantêm com as bromélias nas quais vivem. Entretanto, pelo fato de tais estudos serem ainda recentes, não se sabe sobre a freqüência de especificidade dessas aranhas com espécies de bromélias e como tais associações evoluíram: decerto um campo fecundo de investigações ecológico-evolutivo, como os próprios autores sugerem neste interessante capítulo.

Recentemente tem surgido muito interesse sobre a importância das interações entre espécies para a manutenção e funcionamento de ecossistemas. Nico Blütgen (capítulo 13) aborda interações plantas-animais e importância funcional da biodiversidade. Esse tema tem muito interesse tendo em vista a atual crise de biodiversidade especialmente diante da necessidade de mostrar economicamente a importância dos serviços ambientais executados por espécies silvestres.
Porém, a abordagem do autor é básica, pois reúne argumentos válidos, se bem que indiretos, para mostrar que a evolução da biodiversidade é importante para que várias funções que diferentes espécies desempenham mantenham a integridade de ecossistemas. Apesar de não tratar em detalhes sobre a ecologia-evolutiva da diversidade funcional, é um capítulo importante na estrutura do livro pelas razões acima expostas.

No capítulo 14, Thomas M. Lewinsohn, Leonardo Ré Jorge \& Paulo Inácio Prado assinalam a existência de duas abordagens que podem ser empregadas a fim de se compreender a relação entre a diversidade de herbívoros e plantas. A primeira é a de observar a variação da diversidade de ambos os grupos com o objetivo de detectar a ocorrência de correlações ou padrões generalizáveis. A outra é a da investigação sobre quais seriam os processos ecológicos que originam os padrões. Apesar de não ser tema central do livro, seria bem-vinda uma discussão sobre o impacto destes conhecimentos teóricos sobre a conservação da diversidade de interações plantas-herbívoros, o que poderia ser recomendado em uma possível edição futura.

Apesar de ter certa reserva quanto a opção dos organizadores em dividir arbitrariamente as partes II e III, Judith L. Bronstein (capítulo 15) resgata o aspecto dinâmico existente entre antagonismos e mutualismos, discutindo como tais interações interespecíficas podem interagir entre si. Em suas conclusões indica que estudos ecológicos sobre mutualismos devem ser abordados em uma perspectiva de ecologia de comunidades, não apenas de interações em duas populações, para que seus significados sejam satisfatoriamente compreendidos.

No capítulo conclusivo do livro (capítulo 16), onde apresenta qual deve ser o norte dos estudos sobre interações plantasanimais, John N. Thompson argumenta que a coevolução é muito mais difundida do que antes se suspeitava. Neste caso, um aspecto teórico importante a ser perseguido é o problema sobre como se dá a diversificação da vida em ambientes terrestres, considerando-se que as modificações coevolutivas entre plantas e herbívoros podem ser a sua causa mais importante. A leitura desse capítulo certamente informará aos leitores sobre questões teóricas importantes no âmbito da ecologia-evolutiva.

Dentre as razões pelas quais esse livro deve ser lido e consultado por estudantes de biologia, ciências ambientais e geografia, se destacam a sua abrangência, que permitirá aos alunos estudar e entender a diversidade de abordagens atuais que compõe o tema, e a acessibilidade da obra pelo fato de estar redigida em português. 